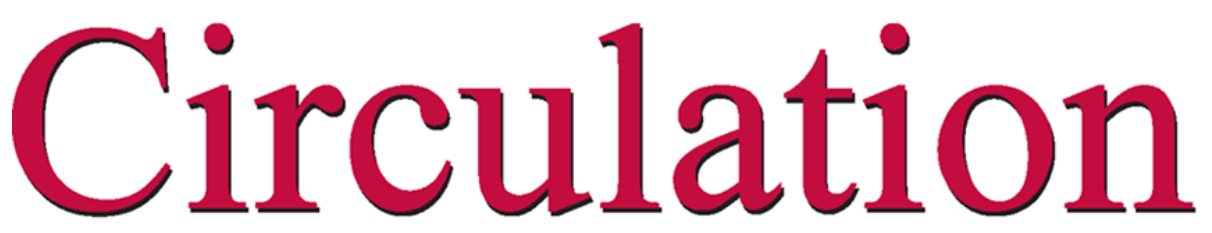

JOURNAL OF THE AMERICAN HEART ASSOCIATION
American Heart Association

Learn and Live

\title{
Improved Regional Wall Motion 6 Months After Direct Myocardial Revascularization (DMR) With the NOGA DMR System
}

Glenn Van Langenhove, Jaap N. Hamburger, Peter C. Smits, David P. Foley, Mariano Albertal and Patrick W. Serruys

Circulation 2000;102;44-45

Circulation is published by the American Heart Association. 7272 Greenville Avenue, Dallas, TX 72514

Copyright (C) 2000 American Heart Association. All rights reserved. Print ISSN: 0009-7322. Online ISSN: $1524-4539$

The online version of this article, along with updated information and services, is located on the World Wide Web at: http://circ.ahajournals.org/cgi/content/full/102/7/e44

Subscriptions: Information about subscribing to Circulation is online at http://circ.ahajournals.org/subsriptions/

Permissions: Permissions \& Rights Desk, Lippincott Williams \& Wilkins, 351 West Camden Street, Baltimore, MD 21202-2436. Phone 410-5280-4050. Fax: 410-528-8550. Email: journalpermissions@1ww.com

Reprints: Information about reprints can be found online at http://www.lww.com/static/html/reprints.html 


\title{
Improved Regional Wall Motion 6 Months After Direct Myocardial Revascularization (DMR) With the NOGA DMR System
}

\author{
Glenn Van Langenhove, MD; Jaap N. Hamburger, MD; Peter C. Smits, MD; David P. Foley, MD; \\ Mariano Albertal, MD; Patrick W. Serruys, MD
}

\begin{abstract}
A 60-year-old man was referred to our intervention laboratory for direct myocardial revascularization (DMR). He had received maximal medical therapy and had undergone coronary bypass surgery 10 years earlier, and his peripheral coronary anatomy was now found to be unsuited for surgical revascularization. In addition, the lesions on coronary angiography proved to be unfit for percutaneous revascularization. Consequently, a DMR procedure was performed. We used the NOGA nonfluoroscopic electromechanical mapping system (Biosense-Webster) as a guidance tool to deliver laser energy at the exact target locations. The system has been described previously.1,2 In the Figure, A shows the local linear shortening (LLS) map in the left anterior oblique view and its corresponding bull's-eye view $\left(\mathrm{A}^{\prime}\right)$ at baseline. The map is color-coded (see color bar in B), ranging from red (LLS $<2 \%$ ) to purple (LLS $>11 \%$ ), with red zones thought to delineate akinetic zones and purple normokinetic zones. ${ }^{2}$ The bull's-eye view shows basal (outer circle), mid, and apical (inner circle) regions of (clockwise from top) the anterior (small A), lateral $(\mathrm{L})$, posterior $(\mathrm{P})$, and septal $(\mathrm{S})$ segments. In the picture, the low LLS values in the basal and mid portions of the posterior and lateral segments can be seen $(-1.4 \%,-2.5 \%, 2.2 \%$, and $4.1 \%$, respectively). Because the unipolar voltage map suggested viability, these regions were
\end{abstract}

thought to be eligible for DMR. B and B' show the LLS map after the DMR procedures, with the brown tags showing the precise locations of the laser energy applications. Similar LLS values in this region support the belief that regional wall motion improvement can be expected only after a certain time delay and not immediately after DMR.

The control map taken at 6 months is shown in $\mathrm{C}$ and $\mathrm{C}^{\prime}$. The improvement of regional wall motion can easily be appreciated in C. Indeed, the posterolateral zone, formerly colored red, is now green-blue, suggesting increased LLS and thus improved wall motion. The bull's-eye shows increases in LLS of $2.9 \%, 7.1 \%, 4.3 \%$, and $7.2 \%$ for basal and mid portions of the posterior and lateral segments, respectively (average increase, $4.8 \pm 3.3 \%$ ).

This case suggests, for the first time, a local shortening increase as a function of left ventricular wall motion improvement 6 months after a DMR procedure.

\section{References}

1. Ben-Haim SA, Osadchy D, Schuster I, et al. Nonfluoroscopic, in vivo navigation and mapping technology. Nat Med. 1996;2:1393-1395.

2. Kornowski R, Hong MK, Gepstein L, et al. Preliminary animal and clinical experiences using an electromechanical endocardial mapping procedure to distinguish infarcted from healthy myocardium. Circulation. 1998;98:1116-1124.

From the Thoraxcenter, Heart Center, Dijkzigt Hospital, Erasmus University Rotterdam, Netherlands.

Reprint requests to Professor Patrick W. Serruys, Head of the Department of Interventional Cardiology, Thoraxcenter Bd 418, University Hospital Dijkzigt, Dr Molewaterplein 40, 3015 GD Rotterdam, Netherlands. E-mail serruys@card.azr.nl

The editor of Images in Cardiovascular Medicine is Hugh A. McAllister, Jr, MD, Chief, Department of Pathology, St Luke's Episcopal Hospital and Texas Heart Institute, and Clinical Professor of Pathology, University of Texas Medical School and Baylor College of Medicine.

Circulation encourages readers to submit cardiovascular images to the Circulation Editorial Office, St Luke's Episcopal Hospital/Texas Heart Institute, 6720 Bertner Ave, MC1-267, Houston, TX 77030.

(Circulation. 2000;102:e44-e45.)

(C) 2000 American Heart Association, Inc.

Circulation is available at http://www.circulationaha.org 


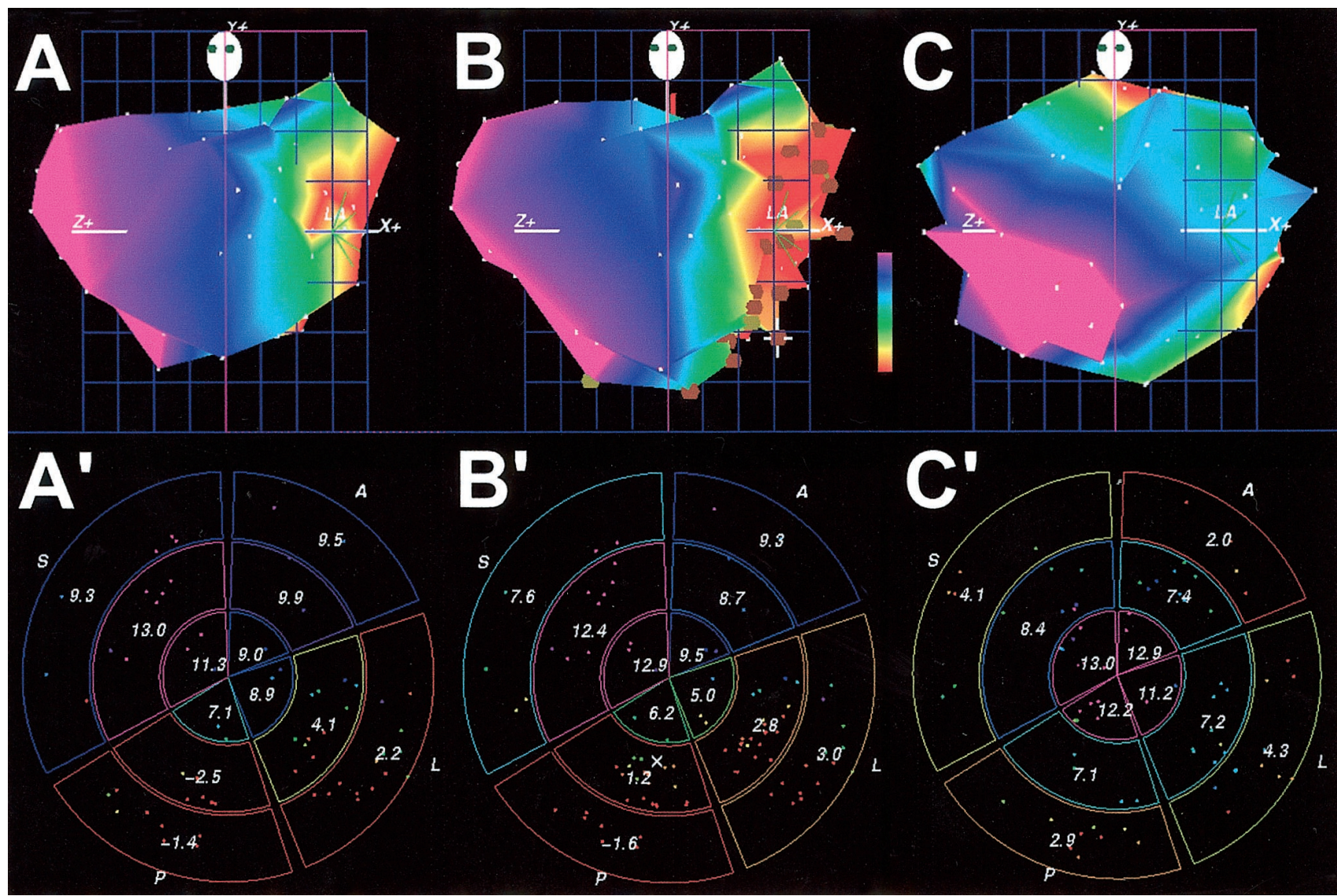

